\title{
EL PODER DISCRECIONAL DE LOS JUECES*
}

\author{
Mario Masciotra**
}

\section{RESUMEN}

La "discrecionalidad judicial" resulta de la indeterminación del Derecho, implica libertad de elección y de selección, integra los poderes-deberes del juez que les confiere y les impone el ordenamiento jurídico. Consiste en la capacidad de discernir la solución justa entre diferentes parámetros, en definitiva, es el poder de decidir libre y prudencialmente en el marco de la ley y conlleva inexorablemente a la independencia del magistrado. Jamás se lleva a cabo en forma absoluta e indeterminada, siempre debe ser debidamente fundada y se encuentra sujeta al control de racionalidad y razonabilidad. Más que una prerrogativa debe ser entendida en términos de responsabilidad jurisdiccional.

Palabras clave: Discrecionalidad judicial.

\section{Abstract}

The "judicial discretion" results from the indeterminacy of the law, implies choice and selection freedom, integrates the judge powers-

Recibido: octubre 10 de 2014 - Aceptado: junio 02 de 2015

* Artículo inédito.

** Profesor emérito y titular de cátedra de grado de Derecho Procesal Civil y Comercial y Profesor de "Hábeas Data" en postgrado de la Universidad del Salvador. Director del Instituto de Derecho Procesal de la Facultad de Ciencias Jurídicas de la Universidad del Salvador (11.8.2008 hasta la fecha). Autor de un centenar de artículos, colaboraciones, comentarios de fallos y ponencias; director-coordinador de un decena de obras colectivas, como asimismo autor de cuatro libros: Acción subrogatoria (1999); Hábeas Data: una garantía polifuncional (2003); La conducta procesal de las partes (2005) y El principio de congruencia en los procesos civiles patrimoniales y de familia, laborales y colectivos ambientales (2010). 
duties conferred and imposed by the juridical system. Consists in the ability to discern between different parameters a just solution, in definitive, is the power to decide freely and prudently within the framework of the law and leads inexorably to the magistrate independence. It is never done by an absolutely and indeterminate form, should be always well-founded and subject to the control of rationality and reasonableness. More than a prerogative, it must be understood in terms of jurisdictional responsibility.

Key words: Judicial discretion.

\section{INTRODUCCIÓN.}

A partir de las enseñanzas de Hans Kelsen, que recepcionó y condensó el pensamiento positivista del siglo XIX, se percibe con claridad que el derecho está siempre y necesariamente indeterminado. El sistema jurídico se estructura, según el insigne jurista austriaco, en forma piramidal, en escalones o niveles, cada uno de los cuales es concreción del anterior, del que extrae su validez y, en una u otra medida, también su contenido. Esa concreción o determinación no es nunca, sin embargo, completa, bien porque conscientemente se pretenda dejar a los órganos inferiores un margen de decisión o bien porque puede ser la consecuencia no buscada de la forma de ser de la norma jurídica que debe ser aplicada mediante el acto en cuestión. Así surge en opinión del refulgente pensamiento kelseniano la indeterminación intencional o no intencional del acto de aplicación de Derecho ${ }^{1}$.

Será intencional la indeterminación cuando emerge de la voluntad del órgano que instauró la norma que ha de aplicarse. Así, la promulgación de una norma meramente general se efectúa siempre, conforme a su naturaleza, bajo el supuesto de que la norma individual que surgirá de su aplicación continuará el proceso de determinación que configura el sentido mismo de la secuencia graduada de normas jurídicas ${ }^{2}$.

Pero la indeterminación puede ser la consecuencia no buscada de la forma de ser de la norma jurídica que debe ser aplicada mediante el acto en cuestión. Es sabido que el lenguaje del Derecho se caracteriza por su vaguedad, ambigüedad y textura abierta que admite una interpretación tanto restrictiva como extensiva ${ }^{3}$,

1 KELSEN, Hans. Teoría pura del derecho. Traducido por Roberto J. Vernengo. México: UNAM, 1979. pp. 350-351.

2 Ibídem.

3 CARRIÓ, Genaro R. Notas sobre Derecho y lenguaje. 2a ed. Bs. As: Ed. Abeledo-Perrot, 1979. p. 27. 
lo que genera zonas de certeza y zonas de incertidumbre e influye en la complejidad del proceso de interpretación que conduce a que los magistrados tengan que crear la norma concreta aplicable al caso.

A ello se suma la imposibilidad que tiene el legislador para predeterminar todas las conductas humanas posibles, por cuanto la ley escrita es incapaz de resolver todos los problemas suscitados en las relaciones sociales. Las necesidades de la comunidad son tan variadas, el comercio entre los hombres es tan activo, los intereses son tan múltiples, sus vinculaciones son tan extensas que es imposible al legislador preverlo todo. Esta situación provoca un ancho cauce para que la discrecionalidad se manifieste tanto frente a las presencia de normas incompletas como a los vacíos normativos.

La indeterminación del acto jurídico que haya de efectuarse puede resultar asimismo, como consecuencia de la vigencia de dos normas -contenidas o no en la misma regulación legal- que se contradicen total o parcialmente.

Sin lugar a dudas entonces, esta indeterminación del Derecho conduce inevitablemente a la discrecionalidad del magistrado en el dictado de su pronunciamiento de aplicación del Derecho.

Por otra parte, la fragmentación del principio de legalidad, que ahora comienza a reconocerse en el Derecho europeo, presente en la estructura del Derecho comunitario, ha provocado la ruptura del monopolio de la ley por el legislativo y aun cuando la ley sigue conservando una jerarquía superior a los reglamentos y a otras fuentes, debe convivir en el plano interno con los principios generales del Derecho que vienen a limitar los poderes del legislador y, con las fuentes del Derecho comunitario o de la integración en América del Sur, que tipifican un derecho supranacional ${ }^{4}$ (por imperio del art. 75 inc. 22 de la Constitución Nacional de la República Argentina ciertos tratados revisten raigambre constitucional).

Cabe destacar que, en la actualidad, la doctrina ha tratado de superar el tradicional esquema dualista circunscripto a la interpretación y creación del Derecho poniendo el acento en la función de integración ${ }^{5}$, que lleva a cabo el juez al cubrir los vacíos legislativos o lagunas ${ }^{6}$.

$4 \quad$ CASSAGNE, Juan C. "La discrecionalidad administrativa y el control judicial". Rev. La Ley, Bs. As: Ed. La Ley SAE e I. To 2008-E. p. 1056.

5 BIDART CAMPOS, Germán J., Tratado elemental de Derecho constitucional argentino. Bs. As: Ed. Ediar, 1989. To I. p. 69.

$6 \quad$ VIGO, Rodolfo L. De la ley al derecho. México: Ed. Porrúa, 2005. pp. 102-103. 
Esto tiene trascendencia -afirma Cassagne ${ }^{7}$-, en materia de discrecionalidad habida cuenta de que las dificultades que provocaron la abstención de los jueces para entender en su juzgamiento obedecieron, en gran medida, a los dogmas del positivismo legalista de Kelsen ${ }^{8}$, particularmente al dogma de plenitud o hermeticidad del ordenamiento normativo, que es algo muy diferente al orden jurídico compuesto solo por normas, sino que más bien corresponde al autointegrado con los principios generales del Derecho emanados del ordenamiento o de la justicia material (heterointegración) ${ }^{9}$.

\section{CONCEPTUALIZACIÓN DE LA DISCRECIONALIDAD JUDICIAL.}

El tema -como es lógico suponer- ha generado desde antaño profundos debates y serias controversias; incluso se sostiene la inexistencia de toda discrecionalidad judicial, por cuanto el juez, conocedor del Derecho, al adoptar una decisión dentro de los márgenes que le confiere las normas jurídicas, ella no surge de su propia voluntad, sino que es la imposición del Derecho mismo que sirve de sustento a aquella.

En mi opinión, en la medida en que las disposiciones legales otorgan márgenes de libertad al juez para adoptar un pronunciamiento, estamos frente a un poder discrecional del magistrado, la discrecionalidad está dada por la capacidad de discernir la solución justa entre diferentes parámetros, en definitiva, es el poder de decidir libre y prudencialmente en el marco de la ley.

La trascendencia del tema en cuestión mereció un amplio análisis y desarrollo en el Coloquio Internacional desarrollado durante los días 25 a 28 de

$7 \quad$ CASSAGNE. Op. cit. p. 1056.

8 DWORKIN, Ronald. Los derechos en serio. Traducido por Marta Guastavino. Barcelona: Ed. Ariel, 1992. p. 83.

9 Afirma Bidart Campos que la concepción dogmática y absoluta de la plenitud del ordenamiento positivo resulta imposible de sostener frente a la realidad que exhibe el mundo normativo frecuentemente indeterminado o incompleto, con innumerables vacíos o lagunas. Si en tales casos hay que acudir a los principios generales del Derecho, ello demuestra que el ordenamiento positivo no es hermético. Con todo, la idea de plenitud del ordenamiento puede aceptarse a condición de que no se la asocie al positivismo legalista, ya que las lagunas jurídicas resultan cubiertas con la integración de principios de justicia que están fuera del ordenamiento positivo (heterointegración) o principios generales del Derecho que están dentro de dicho ordenamiento y que se aplican por analogía (autointegración). El salto a la justicia material solo es posible cuando no se puede llevar a cabo este último proceso de integración dentro del ordenamiento positivo. BIDART CAMPOS. Op. cit. pp. 69-70. 
abril de 2000 en Gante (Bélgica), organizado por la Asociación Internacional de Derecho Procesal; y habida cuenta de la diversidad de ópticas y criterios que se sustentan en distintas y variadas latitudes, es digno sintetizar algunas de las exposiciones brindadas por los eximios procesalistas intervinientes al aludido evento académico ${ }^{10}$.

Tal el caso de Burkard Hess (Alemania) quien sostuvo que el concepto de discrecionalidad judicial es inherente a todo sistema jurídico, que existen divergencias de criterios, pero en general rige una tendencia hacia la amplitud de la misma. No cabe duda que el concepto "discrecionalidad judicial" es un término impreciso, que implica libertad de elección y de selección, que forma parte de los deberes y de los poderes inherentes al juez y conlleva inexorablemente a la independencia del magistrado. Jamás se lleva a cabo en forma absoluta e ilimitada, siempre es en forma guiada, conforme a las pautas de la razonabilidad y el respeto del principio de la proporcionalidad; el control de la discrecionalidad es ejercido por las partes a través de la facultad recursiva.

Ignacio Díez-Picazo (España) puntualizó que en la doctrina ibérica se presentan dos posturas: para unos, la discrecionalidad jurídica es un fenómeno inexistente pues se la identifica con la facultad de interpretar la ley, la que es inherente a la actividad jurisdiccional; la misma solo puede ser entendida como mayor libertad en la interpretación de las normas, en los casos en que ellas contengan conceptos amplios e imprecisos, pero no como facultad de opción entre varias soluciones jurídicamente correctas. Para otros, existe un amplio número de potestades discrecionales de los jueces en la dirección del proceso, mientras que en la apreciación de los hechos y en la decisión de fondo la discrecionalidad debe considerarse un fenómeno residual.

En Brasil -expuso Ada Pellegrini Grinnover-, el poder discrecional del juez es amplio, inserto en la concepción del activismo judicial que impera en la doctrina y legislación brasileña, aunque la misma, siempre debe ser motivada, fundada y revisada por la alzada; el control se efectiviza mediante el criterio de justicia, de la finalidad social y el principio de proporcionalidad o razonabilidad.

Resultó interesante la visión china sobre el tema que expuso Ji Wiedong: la mayor parte de los pronunciamientos judiciales que se dictan en dicho país, se fundamentan en la interpretación abierta de la ley fundada en la subjetividad; no hay determinismo, sino una gran flexibilidad, en atención a ello, la capacidad psicológica del juez tiene un rol protagónico. Señaló, que a partir de 1993 se ha implementado una serie de garantías tendientes a evitar la arbitrariedad que

$10 \quad$ Para mayor ilustración, ver MASCIOTRA, Mario. "Un Derecho Procesal para todos los tiempos... Desde Carlos V al tercer milenio". Rev. de Derecho Procesal. No 5, Sta. Fé: Ed. Rubinzal-Culzoni , 2000. p. 517. 
genera el subjetivismo de los magistrados y concluyó afirmando que el poder discrecional judicial se manifiesta en la libre evaluación de las pruebas y en la libre decisión de los conflictos teniendo en cuenta los intereses de las partes y las normas legales vigentes.

El Profesor Neil Andrews anunció que en 1999 se sancionaron en Inglaterra normas de procedimientos civil que otorgan una mayor discrecionalidad judicial ${ }^{11}$ y acotó que estas reformas han variado el estilo de los jueces y no pocos poseen la suficiente capacidad para ejercer plenamente las atribuciones otorgadas y, por otra parte, las decisiones judiciales en ejercicio de esa mayor discrecionalidad han tomado de sorpresa a los litigantes acostumbrados a una pasividad conservadora de los magistrados ingleses.

A modo de colofón, el enjundioso procesalista inglés señaló los peligros y las ventajas de la discrecionalidad judicial. Entre los primeros, mencionó: 1) Subjetividad: es injusto que dependa del temperamento del juez; 2) Incoherencia: es inadmisible que se apliquen criterios disímiles para casos iguales, pues se deteriora la seguridad jurídica; y 3) Vergüenza judicial: no puede atentarse contra el criterio de la comunidad, los pronunciamientos deben asentarse en el sentido común (como la lógica y la experiencia), habida cuenta de que el juez no puede incurrir en el absurdo, es decir, dictar pronunciamientos ilógicos o disparatados. La discrecionalidad judicial irrestricta e ilimitada puede configurar "la tiranía judicial". A continuación, esbozó sus ventajas, que consisten en: 1) impedir que el tribunal se encuentre limitado a ritos formales; 2) implica que la ley sea interpretada; 3 ) simplifica los procedimientos al reducir la complejidad de las normas procesales; y 4) entraña ejercicio de la soberanía.

En definitiva, estas son diferentes ópticas y distintos criterios que con sumo rigor científico enriquecen nuestra visión de la discrecionalidad judicial.

\section{DEBATE HART - DWORKIN. DISTINCIÓN ENTRE CASOS FÁCILES Y DIFÍCILES.}

El célebre debate entre los Profesores Herbert Lionel Adolphus Hart y Ronald Dworkin, nos proporciona interesantes elementos para dilucidar los alcances de

11 Entre los poderes conferidos a los jueces, aludió a: 1) aplazar la vista de causa, suspender la misma, determinar el orden de los temas a tratarse; 2) adoptar medidas sin instancia de parte y dictar resoluciones tendientes a hacer progresar eficazmente la causa; 3) suprimir puntos de defensa con base en que carecen de fundamentación, incurren en abuso de procedimientos, obstaculizan la justicia o por violación de normas u órdenes procesales; 4) sugerir a las partes la adopción de métodos alternativos de solución de conflictos. MASCIOTRA, Mario, publicación citada. 
la materia en cuestión, puesto que uno de los temas de mayor enfrentamiento entre ambos fue el de la "discrecionalidad judicial" en los casos difíciles. Al seguir el Estudio Preliminar de César Rodríguez ${ }^{12}$ afirmamos que en términos generales, un caso es difícil cuando los hechos y las normas relevantes permiten, por lo menos a primera vista, más de una solución. El tipo de caso difícil más frecuente es aquel en el que la norma aplicable es de textura abierta, es decir, contiene una o más expresiones lingüísticas vagas. Al formular su teoría sobre la discrecionalidad judicial, Hart tuvo en mente este tipo de caso, como lo muestra el ejemplo en el que se discute si la regla "está prohibida la circulación de vehículos en el parque" se aplica tanto a los automóviles como a las bicicletas.

Dworkin le adiciona al caso aludido cuatro alternativas: a) es factible que exista más de una norma aplicable al caso, como sucede cuando dos principios colisionan; b) cuando no existe ninguna norma aplicable, es decir, hay una laguna en el sistema jurídico, en cuyo caso se resuelve por medio de mecanismos de integración, como la analogía; c) aunque exista una sola norma pertinente y su texto sea claro, su aplicación puede ser injusta o socialmente perjudicial en el caso concreto, lo que explica la autorización excepcional al juez para acudir a la equidad como criterio de decisión; y d) es posible que el juez o tribunal haya establecido un precedente que a la luz de un nuevo caso considere necesario modificar, el cambio de jurisprudencia implica una carga argumentativa superior a la de los casos rutinarios ${ }^{13}$.

Dos teorías jurídicas radicales y opuestas se han disputado a lo largo del siglo pasado la preeminencia en la explicación del razonamiento jurídico. De un lado, el formalismo que sostiene que la división entre casos fáciles y difíciles es artificiosa, pues los jueces, en todas las circunstancias, deciden de acuerdo con el Derecho. De otro lado, el realismo jurídico defiende una posición escéptica frente a las normas jurídicas, estas solo juegan un papel marginal en las decisiones judiciales, es la voluntad de los jueces, no las normas, la que se impone en las sentencias.

Hart critica tanto la versión formalista como la realista del razonamiento jurídico $^{14}$ y afirma que la verdad se encuentra en el medio del formalismo y el

12 RODRÍGUEZ, César. La decisión judicial. El debate HART - DWORKIN. Bogotá: Ed. Siglo del Hombre, Univ. de los Andes, 1997. p. 66 y ss.

13 DWORKIN, Roland. "Judicial Discretion”. The Journal of Philosophy. № 60, 1963, pp. 624-638, citado por RODRÍGUEZ. Op. cit. p. 68.

14 Contra el formalismo señala la existencia de casos difíciles, en los que es insostenible la tesis según la cual las normas determinan claramente un resultado. Contra el realismo, muestra que la práctica cotidiana del Derecho consiste en la solución de casos fáciles, en que los jueces no dudan en aplicar de manera rutinaria una norma prevista específica- 
realismo, pues en los casos fáciles, la descripción formalista es más acertada, basta un silogismo para conectar la norma con la solución, mientras que en los casos difíciles, la posición realista es la más adecuada, dado que el juez no cuenta con normas precisas, debe elegir entre alternativas razonables: la sentencia, en estas circunstancias, es esencialmente lo que el juez quiera que ella sea, aunque dentro de límites que los realistas pasan por alto. La existencia de estos casos provoca que el Derecho cumpla su segunda función: dejar un margen de flexibilidad a la regulación de las relaciones sociales, que permita considerar las circunstancias del caso concreto ${ }^{15}$.

Para Hart, cuando existe más de una posibilidad de solución, el juez tiene "discrecionalidad" para escoger una de ellas, pues define ex postfacto los derechos y deberes que tienen las partes involucradas en el litigio ${ }^{16}$. El interrogante que se impone es si los jueces tienen algún límite en estos casos de legislaciones excepcionales - “intersticiales", en términos de Hart-. Dworkin afirma que, según la teoría hartiana de los casos difíciles, dicho interrogante conlleva a una respuesta negativa radical ${ }^{17}$. Sin embargo, es posible deducir de las afirmaciones del primero dos límites al poder creativo de los jueces. En primer lugar, por cuanto estos no pueden dictar cualquier solución en un caso difícil, debe estar circunscripta por el texto de las normas aplicables, si estas existen, o por el de las normas y precedentes judiciales que tratan temas similares, en el caso contrario, o criterios "extra-jurídicos", como los principios morales ${ }^{18}$. Están descartadas las soluciones que impliquen violaciones de principios procesales del sistema jurídico. En segundo lugar, está un límite de otra naturaleza, consistente en la existencia de virtudes judiciales, que son la imparcialidad y la neutralidad al examinar las alternativas, consideración de los intereses de todos los afectados y una preocupación por desarrollar algún principio general aceptable como base razonada para la decisión. En todo esto aparece la "ponderación" y el "balance" característicos del esfuerzo por hacer justicia en medio de intereses en conflicto ${ }^{19}$.

mente para un cierto hecho. HART, Herbert L. A. El concepto de derecho. Traducido por Genaro Carrió. Bs. As: Ed. Abeledo-Perrot, 1963. pp. 161-176.

15 Ibídem. p. 183. Para Hart, el Derecho concilia dos necesidades sociales: de un lado, la necesidad de que existan reglas ciertas que regulen la conducta de los individuos, y del otro, la necesidad de dejar abiertos asuntos que se pueden definir adecuadamente solo en cada caso concreto. El derecho se mueve así, entre la seguridad y la equidad. Ibídem. p. 162.

16 Ibídem. p. 164.

17 RODRÍGUEZ. Op. cit. p. 71.

18 HART. Op. cit. pp. 190-191.

$19 \quad$ Ibídem. p. 253. 
La teoría hartiana sobre los casos difíciles es insatisfactoria para Dowrkin tanto desde el punto de vista descriptivo como del punto de vista justificativo ${ }^{20}$. En cuanto a lo primero, la idea de discrecionalidad judicial supone que cuando los jueces afirman en sus sentencias que la interpretación que defienden es la correcta de acuerdo con el Derecho vigente, están utilizando una figura retórica para encubrir lo que realmente es una decisión discrecional. Por otra parte, el ejercicio de potestades legislativas por parte de los jueces, funcionarios designados por vías diferentes a la elección popular, desvirtúa el principio democrático y significa una ocupación del ámbito de competencia de otros poderes públicos. Asimismo, se viola el principio de legalidad, pues según la descripción de los casos difíciles ofrecido por Hart, dado que no hay normas claras, ninguna de las partes involucradas tiene derechos ni deberes antes de que el juez los establezca ex post facto en la sentencia, lo cual constituye una aplicación retroactiva del Derecho, que contraría el principio aludido ${ }^{21}$.

El rechazo de la tesis de la discrecionalidad judicial, según Dworkin, abre el camino para la formulación de un modelo descriptivo-justificativo adecuado a la solución de casos difíciles en el contexto de un Estado democrático de derecho. El primer elemento del modelo ya se encuentra en la distinción entre principios y reglas; es posible que no exista una regla prevista para los hechos de un caso difícil, siempre se podrán aplicar, sin embargo, estas deben ser reglas análogas o principios generales del ordenamiento. Si bien un sistema conformado por reglas tiene lagunas, la inclusión de los principios garantiza la completud del mismo $^{22}$.

El segundo elemento del modelo es introducido por Dworkin para resolver los casos en que la dificultad proviene de la colisión de dos o más principios relevantes. La tesis de la discrecionalidad de los jueces puede ser refutada solo si se propone algún orden jerárquico entre diferentes tipos de principios; si el juez está obligado a preferir cierta clase de principios sobre otra, su poder discrecional desaparece. La distinción dworkiana entre "políticas" -estándares que buscan proteger un "objetivo colectivo", como la seguridad nacional o el crecimiento de la economía- y "principios" -estándares que defienden un "derecho individual", como el libre desarrollo de la personalidad; su justificación es de tipo moral y no depende del provecho que la comunidad obtenga de su existencia ${ }^{23}$ busca establecer las líneas generales de ese orden jerárquico. En

20 DWORKIN, Roland. "Taking Rights Seriously”, Cambridge: Harvard University Press, 1977. pp. 31-39, citado por RODRÍGUEZ. Op. cit. p. 75.

$21 \quad$ Ibídem. p. 86.

$22 \quad$ Ibídem. p. 116.

$23 \quad$ Ibídem pp. 22-28 y 82-84. 
función de dicha distinción, sostiene Dworkin que los jueces fundan y deben fundar sus decisiones en argumentos de principio, sus razones no son de conveniencia social, sino de consistencia jurídica y moral.

La diferenciación entre principios y políticas ha generado numerosas críticas por dos motivos importantes. De un lado, los dos conceptos no son opuestos, porque es posible en muchas ocasiones traducir una política en términos de derechos. De otro lado, los derechos de segunda generación consagrados en las constituciones del Estado social son el resultado de una mezcla de principios y políticas. De hecho, es posible concebir estos derechos como una juridización de estándares que en el Estado liberal funcionaban como políticas dependientes del buen funcionamiento de la economía. La juridización implica la posibilidad de que los individuos puedan exigir por vía judicial las prestaciones estatales previstas en las normas que consagran estos derechos; el juez, en estas circunstancias, debe tener en cuenta necesariamente argumentos de políticas, como los efectos de la protección de un derecho en la marcha de la economía.

El modelo de decisiones judiciales basado en principios, para Dworkin, explica y justifica adecuadamente el papel de los jueces en un Estado democrático de derecho, pues, por una parte, las sentencias no son retroactivas porque los principios que las fundan hacen parte del ordenamiento jurídico antes de ser citados en ellas y, por otra parte, el hecho de que los jueces no sean elegidos popularmente no les impide sino que los "autoriza" a decidir los casos difíciles con argumentos de principio ${ }^{24}$.

La teoría del Derecho como integridad sustentada por Dworkin ${ }^{25}$ diluye dos dilemas derivados del positivismo. En primer lugar, deja sin fundamento la dicotomía entre descubrimiento y creación judicial del Derecho, el juez hace las dos cosas y no hace ninguna al decidir un caso. En segundo lugar, destruye la distinción entre casos fáciles y difíciles; para decidir "cualquier" caso el juez debe examinar las reglas, principios y antecedentes relevantes y decidir cuál es la solución que mejor encaja en esas prácticas jurídicas y está mejor justificada

24 DWORKIN, Ronald. Taking Right Seriously. p. 85, citado por RODRÍGUEZ. Op. cit. p. 80.

25 DWORKIN ha defendido la idea de la integridad bajo la forma de un derecho de todos los ciudadanos a ser tratados con "igual consideración y respeto". Este derecho es la piedra angular del sistema constitucional de los EE.UU. al afirmar que "las autoridades públicas deben tratar a todos los gobernados como titulares de un estatus moral y político igual; deben intentar, de buena fe, tratarlos con igual consideración; y deben respetar todas las libertades individuales que sean indispensables para esos fines (...)". DWORKIN, Ronald. Fredom's Law. The Moral Reading of the American Constitution. Cambridge: Harvard University Press, 1996. pp. 7-8, citado por RODRÍGUEZ. Op. cit. p. 65, nota 137. 
por los valores supuestos por ellas. El método es el mismo en todos los casos; la facilidad o dificultad no aparece al comienzo sino al final del análisis de un problema jurídico. No existe, en definitiva, ninguna distinción sustancial entre casos rutinarios y casos difíciles que dé lugar a que el Derecho opere en aquellos y la discrecionalidad en estos ${ }^{26}$.

Sostiene César Rodríguez que las últimas versiones del debate entre Hart-Dworkin, muestran una cercanía mayor entre las dos posiciones, por cuanto el primero reitera que el poder discrecional no es arbitrario y el segundo sostiene que para interpretar las convicciones subyacentes a la práctica jurídica de la comunidad, el juez no puede evitar acudir a sus propias convicciones, aunque no para imponerlas sobre las de la comunidad, sino para llegar a estas ${ }^{27}$.

Y concluye exhibiendo un rasgo común a toda la discusión entre las teorías de Hart y Dworkin: "La tesis escéptica de Hart parece describir de manera más adecuada la práctica jurídica, que muestra a los jueces y abogados más inciertos sobre lo que "realmente dice" el Derecho de lo que sugiere la descripción de Dworkin (...). La descripción normativa de la teoría dworkiniana, inexistente en la obra de Hart, es un instrumento poderoso de evaluación y crítica de lo que hacen los jueces en los casos difíciles. Sin duda, el valor de la consistencia reivindicado por el Derecho como integridad es una exigencia que debe hacerse a los jueces en un Estado democrático de derecho. Allí donde Hart provee los elementos descriptivos, Dworkin proporciona los instrumentos para la justificación y la crítica"28

\section{OPINIÓN DE LORENZETTI. DISTINCIÓN ENTRE CASOS FÁCILES Y CASOS DIFÍCILES.}

El actual Presidente del más Alto Tribunal de Justicia de la Argentina ha tratado criteriosa y lúcidamente el tema de la discrecionalidad judicial, en uno de los trabajos más sólidos que se hayan elaborado en materia de "teoría de la decisión judicial”29.

Para diagramar un esquema de razonamiento judicial distingue los casos fáciles de los difíciles. En los primeros supuestos, existe una sucesión argumentativa en el razonamiento legal, integrado por dos pasos: en el primero se aplica

26 DWORKIN, Ronald. Law' Empire. Cambridge: Harvad University Press, 1986. p. 354, citado por RODRÍGUEZ. Op. cit. pp. 81-82.

$27 \quad$ RODRÍGUEZ. Op. cit. p. 84, nota 175.

$28 \quad$ Ibídem. p. 88.

29 LORENZETTI, Ricardo L. Teoría de la decisión judicial. Fundamento de Derecho. Sta. Fé: Ed. Rubinzal-Culzoni, 3a Parte, Cap. I, 2006. pp. 183 y ss. 
el método deductivo que comprende: 1) Delimitar los hechos; 2) Identificar la norma y 3) Deducir la solución del caso. El segundo consiste en el control de la solución deductiva, que implica: 1) Mirar hacia atrás, es decir, hacia los precedentes judiciales que establecieron reglas jurídicas para casos con elementos de hecho similares ${ }^{30}$; 2) Mirar hacia arriba, ser coherente con el resto del sistema jurídico, armonizando las reglas; y 3) Mirar hacia adelante, teniendo en cuenta en el análisis las consecuencias que puede producir la decisión en el futuro, dichas consecuencias, pueden ser generales (exceden el ámbito de las partes intervinientes en el litigio y repercuten sobre la sociedad), jurídicas (la decisión adoptada es un incentivo para conductas futuras de partes no involucradas en el conflicto) y económicas-sociales.

Con relación a los casos difíciles, cuyo distingo no es sencillo, ocurre, según Lorenzetti ${ }^{31}$, en dos tipos de situaciones: a) cuando no se puede deducir la solución de modo simple de la ley, por cuanto hay dificultades en la determinación de la norma aplicable o en su interpretación; o b) es necesario apartarse de la ley, porque es inconstitucional. En estos supuestos, el método deductivo es insuficiente, los pasos señalados precedentemente basados en la deducción de reglas no arrojan una solución o sugieren varias alternativas que obligan al juez a ejercer su discreción basada en criterios de validez material.

En tales supuestos, postula la argumentación jurídica basada en principios, y justifica la decisión en términos de corrección, según los siguientes criterios:

La colisión entre reglas produce el efecto de excluir una, porque el resultado de aplicar las dos es incompatible; se desenvuelve en el plano de la validez formal, al que se aplican los razonamientos señalados para la solución tradicional de las antinomias, es decir, cronológico (la norma posterior prevalece sobre la anterior, exceptuando los supuestos de irretroactividad); jerárquico (la norma superior desplaza a la de rango inferior) y especialidad ( la norma general es desplazada por la especial). La antinomia puede resolverse eliminando a una de las normas, porque la aplicación de una de ellas es excluyente; también puede arribarse a una solución que conserve las dos, pero fijando el sentido de una. La decisión consiste en una opción: una o la otra (las reglas son como las vías del tren se siguen o no, no hay una tercera alternativa $)^{32}$.

30 La Corte Suprema de Justicia de la Nación Argentina ha sostenido que la regla es que sus decisiones se adecuen a sus precedentes por cuanto es indudable la conveniencia de asegurar la estabilidad de su jurisprudencia en tanto no medien razones que hagan ineludible su modificación. Fallos, To 183, p. 409; T² 209, p. 431; T 323, p. 555.

$31 \quad$ LORENZETTI. Op. cit. p.189.

32 Ibídem. pp. 249-251. 
La colisión entre principios y valores no produce un efecto de exclusión, ya que la aplicación de un principio no desplaza al otro, sino que lo precede en el caso concreto. Los principios tienen diferente peso en el caso concreto, pero no son inválidos. La contradicción no puede resolverse señalando que uno de los principios carece de validez y eliminándolo del sistema, ni tampoco consagrando una excepción de validez permanente para el futuro. El conflicto entre principios se soluciona mediante un juicio de ponderación de intereses opuestos, se trata de cuál de los intereses, abstractamente del mismo rango, tiene mayor peso en el caso concreto; la decisión no consiste en una opción, sino en una ponderación ${ }^{33}$.

A modo de conclusión, Lorenzetti sostiene que "La decisión basada en estos procedimientos, cualquiera que sea la solución final, tiene la ventaja de ser explicable en términos razonables y por lo tanto es susceptible de ser debatida en el campo de la discusión democrática o judicial. Este objetivo puede verse oscurecido con la utilización de paradigmas, porque la interpretación de las mismas reglas y principios puede llevar a conclusiones diferentes por la 'ideología' de quien toma la decisión. Estamos aquí en un caso de 'discreción fuerte', que en nuestra opinión debería ser por lo menos expuesta para su conocimiento y debate. Asimismo, entendemos que la decisión en estos casos es armonizar paradigmas que son, en cierto modo, competitivos entre sí o bien presentan límites conflictivos o situaciones que hay que contemplar" ${ }^{\prime 3}$.

\section{CRITERIO CONSECUENCIALISTA Y LA DISCRECIÓN JUDICIAL.}

Merece un apartado especial el análisis consecuencialista que ha adoptado la Corte Suprema de Justicia de la Nación Argentina, como una forma de ejercer una función de control en cuanto a la justeza de la decisión a dictarse y que pone de manifiesto una clara aplicación del poder discrecional.

Sin lugar a dudas las secuelas de los pronunciamientos judiciales deben ser analizadas debidamente y tenidas en cuenta a tenor del contexto social, político y económico que plasma la realidad en oportunidad de dictarse los mismos. Debe tenerse presente la realidad sociológica, los destinatarios, sus necesidades y las

33 Cuando existe un conflicto entre principios, la dimensión "peso" significa que el principio con mayor peso desplaza al menos importante, pues no hay un orden jerárquico vinculante dado con anterioridad que muestre cómo debería resolverse el conflicto; entre los principios existe el llamado orden de preferencia débil, determinado por el orden de preferencia de los valores y fines subyacentes. Ibídem. 
soluciones que mejor pudieren resolver los conflictos de convivencia y evitar que las consecuencias de las disposiciones legales, su espíritu o los estándares interpretativos produzcan resultados complicantes o negativos para la paz social con justicia.

El tribunal cimero argentino ha acunado desde antigua data la pauta de la interpretación previsora o consecuencialista como método válido de despejar el camino justo a seguir tanto en la interpretación de la ley como de la Constitución, al sostener -en fallo de 1956- que estas "deben ser interpretadas en forma coherente, de manera que armonicen entre ellas y no traben el eficaz y justo desempeño de los poderes atribuidos al Estado para el cumplimiento de sus fines del modo más beneficioso para la comunidad y los individuos que la forman (Fallos, T. 183, p. 343; T. 186, p. 170; T. 169, p. 483, entre otros)"35.

Décadas después, ${ }^{36}$ este resolvió que la norma específica -art. 13, Ley de trasplantes 21.541- "ha de ser interpretada considerando armónicamente la totalidad del ordenamiento jurídico y los principios y garantías de raigambre constitucional, para obtener un resultado adecuado, atento a las excepcionales particularidades de esta causa, pues la admisión de soluciones notoriamente disvaliosas no resulta compatible con el fin común tanto de la tarea legislativa como de la judicial (...) no debe prescindirse de las consecuencias que naturalmente derivan de un fallo toda vez que constituye uno de los índices más seguros para verificar la razonabilidad de la interpretación y su congruencia con el sistema en que está engarzada la norma" (considerando 2 del voto de los Drs. A. R. Gabrielli y A. F. Rossi).

En dicho pronunciamiento, el tribunal también expresó que "debe evitar que la aplicación mecánica e indiscriminada de la norma conduzca a vulnerar derechos fundamentales y a prescindir de la preocupación por arribar a una decisión objetivamente justa en el caso concreto lo cual iría en desmedro del propósito de 'afianzar la justicia' enunciado en el Preámbulo de la Constitución Nacional" (considerando 7 del voto de los Drs. Gabrielli y Rossi).

"No se trata en el caso de desconocer las palabras de la ley, sino de dar preeminencia a su espíritu, a sus fines, al conjunto armónico del ordenamiento jurídico y a los principios fundamentales del Derecho en el grado y jerarquía en que estos son valorados por el todo normativo, cuando la inteligencia de un precepto basada exclusivamente en la literalidad de uno de sus textos conduzca

35 CSJN., 23.4.1956, “Grisolía, Francisco M.", Rev. La Ley, Bs. As: Ed. La Ley SAE e I. To 82. p. 690.

36 CSJN., 6.11.1980, “Saguir y Dib, Claudia G.", Fallos, To 302, p. 1284; Rev. La Ley, Bs. As: Ed. La Ley SAE e I. Tº.1981-A, p. 401, con nota de Julio R. Méndez. 
a resultados concretos que no armonicen con los principios axiológicos enunciados precedentemente, arribe a conclusiones reñidas con las circunstancias singulares del caso o a consecuencias concretas notoriamente disvaliosas. De lo contrario, aplicar la ley se convertiría en una tarea mecánica incompatible con la naturaleza misma del Derecho y con la función específica de los magistrados que les exige siempre conjugar los principios contenidos en la ley con los elementos fácticos del caso, pues el consciente desconocimiento de unos u otros no se compadece con la misión de administrar justicia" (considerando 12 del voto de los Drs. Gabrielli y Rossi).

Este criterio fue ratificado en "Baliarda S.A. y otros c. Pcia. de Bs. As." c."37 en los siguientes términos: “(...) uno de los índices más seguros para verificar la razonabilidad de la inteligencia de una norma y su congruencia con el resto del sistema a que está engarzada, es la consideración de sus consecuencias (...)”.

Posteriormente, expresó: "Cuando la inteligencia de un precepto, basada exclusivamente en la literalidad de uno de sus textos, conduzca a resultados concretos que no armonicen con los principios axiológicos enunciados en otro de rango superior y produzca consecuencias notoriamente disvaliosas, resulta necesario dar preeminencia al espíritu de la ley, a sus fines, al conjunto armonioso del ordenamiento jurídico y a los preceptos fundamentales del Derecho en el grado y jerarquía en que estos son valorados por el ordenamiento normativo"38.

En los últimos tiempos, en numerosos otros casos, la Corte ha invocado el recurso de la evaluación de las consecuencias para despejar la interpretación justa de la norma en juego (constitucional o legal), y en tal sentido merece destacarse "Filcrosa S.A." de $2003^{39}$ sobre la aplicación de las normas del Código Civil en cuestiones aparentemente regidas por el derecho local y el voto del Dr. Lorenzetti en "Cuello, Patricia D. c. Lucena, Pedro A." ${ }^{40}$, en el que se descalificó el criterio de algunas Salas de la Cámara Nacional en lo Civil -luego devenido en plenario- ${ }^{41}$ acerca de la inoponibilidad de la franquicia de seguro a las víctimas de accidentes de tránsito por cuanto "desnaturalizó la normativa aplicable al asignarle un significado que excede inaceptablemente sus fines y que por eso debe ser descartado" (cons. $8^{\circ}$ ).

$37 \quad$ Fallos, To 303, p. 917, Rev La Ley, Bs. As: Ed. La Ley SAE e I. To 2004-A. p. 127.

38 CSJN., “Bramajo, Hernán”, fallos, To 319, p. 1840.

39 Fallos, To 326, p. 3899.

$40 \quad$ CSJN., 7.8.2007, fallos, To 330, p. 3483; Rev. La Ley, Bs. As: Ed. La Ley SAE e I. To 2007-E. p. 398.

41 Cám. Nac. Civ., en pleno, 13.12.2006, "Obarrio, María P. c. Microómnibus Norte SA. y otro", Rev. La Ley, Bs. As: Ed. La Ley SAE e I. To 2007-A. p. 168. 
Así mismo, en el importante fallo "Massa, Juan J. c. PEN" del 27.12.2006 $6^{42}$ sobre la constitucionalidad de las normas de "pesificación" de los depósitos financieros, reforzó la argumentación desarrollada acudiendo a la interpretación constitucional previsora de las consecuencias.

Para finalizar el segmento y en orden al criterio consecuencialista abordado, debo citar la Acordada 36/2009 dictada el 9.9.2009 por la Corte Suprema de Justicia de la Nación Argentina, en virtud de la cual se crea la "Unidad de Análisis Económico" ${ }^{43}$, que ha generado controvertidas opiniones doctrinarias ${ }^{44}$.

$42 \quad$ Fallos, To 329. p. 5913.

43 Su finalidad es "realizar, por indicación de la Presidencia, los estudios de índole económica necesarios para atender los requerimientos en la materia y la evaluación de los efectos que podrían producirse en las variables económicas, como consecuencia de las decisiones que eventualmente pudieran adoptarse en expedientes en trámite ante el Tribunal". En sus considerandos se sostiene "la necesidad (...) de solicitar una opinión fundada acerca de los efectos macroeconómicos, que derivarían de decisiones que eventualmente puedan adoptarse en expedientes en trámite ante el Tribunal" y efectúa una amplia enunciación de distintos y variados contenidos directamente referidos a cuestiones de naturaleza económica, como temas fiscales, derechos sociales, cuestiones vinculadas al desarrollo humano, intereses económicos, la competencia, el control de los monopolios, el funcionamiento de los servicios públicos, el desarrollo, la calidad de vida, la igualdad de oportunidades, la justicia social, la productividad, el empleo, el valor de la moneda, etc., en síntesis, todo tema vinculado al trabajo, la seguridad social, la salud y el medio ambiente configuran "casos concretos" que serán sometidos a "un razonable juicio de ponderación".

44 Ha merecido serias objeciones de Rodolfo Capón Filas en "Equipo Federal del Trabajo, $\mathrm{n}^{\circ} 53$ del 4.10.2009, www.eft.org.ar; y tachada de inconstitucional por KESELMAN, Pedro J. "La Acordada 36/2009 y la jurisprudencia de la Corte sobre derechos humanos sociales", Rev. La Ley, Bs. As: Ed. La Ley SAE e I. To 2010-D. p. 916; y por CONSTANTE, Liliana B."La abogacía organizada se pronunció en contra de la Acordada 36 CSJN del 09/9/09". Rev. La Ley, Suplemento Actualidad, Bs. As: Ed. La Ley SAE e I. 22.7.2010; como asimismo la reprobación de la XVI Conferencia Nacional de Abogados en el tema "La Economía y el Derecho de Interdependencias, Supremacías y Consecuencias" (Comisión III) organizada por la Federación Argentina de Colegios de Abogados, 7 a 10 de abril 2010. La Comisión de Derecho Procesal Constitucional del XXVI Congreso Nacional de Derecho Procesal llevado a cabo del 8 al 10 de junio de 2011, en Sta. Fé, en una de sus conclusiones afirmó: "La Acordada $\mathrm{N}^{\circ} 36 / 2009$ de la CSJN ha facilitado el aterrizaje formal de la metodología del Análisis Económico del Derecho (AED) en el seno del Tribunal, introduciendo la ponderación económica en un contexto de razonabilidad. Ese análisis permite a la Corte tener un conocimiento adecuado de la realidad jurídica subyacente, contar con una adecuada consistencia técnica en el uso de los conceptos económicos y evaluar técnicamente la idoneidad de una herramienta jurídica para la consecución de su fin, respetando el principio de proporcionalidad. El AED, empleado prudentemente, puede resultar útil para ponderar la potencial incidencia económica de las sentencias judiciales". Rev. La Ley, Suplemento Actualidad, Bs. As: Ed. La Ley SAE e I. 9.8, 2011. 


\section{CONCLUSIONES.}

Ineludible consecuencia del poder-deber de decidir, surge el deber de fundar toda sentencia definitiva o interlocutoria que dicten los magistrados, e ínsito en el mismo se encuentra la "discrecionalidad judicial", definida como la zona de posibilidad entre alternativas legítimas en oportunidad del dictado de un pronunciamiento ${ }^{45}$.

Una de las facetas que asume la "discrecionalidad judicial" es el apartamiento al texto expreso de las normas legales. El recorrido del vasto y complejo historial de la Corte Suprema argentina nos demuestra que en ejercicio de legítimos poderes discrecionales ha dictado fallos sin atenerse a las normativas vigentes, sea cuando su interpretación sistemática así lo impone ${ }^{46}$; cuando el espíritu que nutre las mismas sea lo que debe rastrearse en procura de una aplicación racional que avente el riesgo de un formalismo paralizante ${ }^{47}$; cuando ellas conducen a resultados "tan irrazonables que no sería justo atribuirlos a la intención del Congreso" 48 ; o cuando la expresión literal presenta imperfecciones técnicas, que se contradicen con el espíritu de la ley vinculada con preceptos constitucionales que deben prevalecer ${ }^{49}$.

Otro escenario que exhibe la "discrecionalidad judicial" es indudablemente el activismo judicial -especialmente de los tribunales superiores- a través del gran protagonismo asumido desde principios del siglo pasado, marcando rumbos decisivos en temas trascendentales ${ }^{50}$ y un ejercicio más acentuado al control

45 BARAK, Aharon. "La discrecionalitá del giudice”. Milano: Ed. Giufré, 1995. p. 33.

46 Fallos 283: 239; 301: 489.

$47 \quad$ Fallos 302: 1284; 316: 1025; 316: 3043; 318: 371, entre otros. Andruet denomina "argumento apagógico" el que utiliza "el juez cuando debe efectuar una interpretación normativa en donde la aplicación de dicha regla de derecho importa la generación de una notoria injusticia o inequidad, motivo por el cual, a los efectos de resolver dicha situación, mediante este recurso otorga una voluntad al legislador por la cual lo hace presuponer que no ha querido prever el nombrado situaciones inicuas o irrazonables, por lo cual su gestión le impone orientarse a ello y en tal criterio adecuar la ley al caso concreto y dictar una sentencia razonable y justa". ANDRUET, Armando. Teoría general de la argumentación forense. Córdoba: Ed. Alveroni , 2001. p. 270.

CSJN., fallos 323: 3139, dictamen del Procurador General compartido por la Corte, con cita de fallos 321: 1434 .

50 Consagrando pretorianamente el recurso extraordinario por sentencia arbitraria (Rey c. Rocha, 1909) y el amparo (Siri y Kot, 1957); otorgando facultades judiciales en materia probatoria en procesos civiles (Colalillo, 1957, Coll de García, 1968, Oihler, 1980); definiendo el derecho a la intimidad y a la privacidad (Ponzetti de Balbín, 1984); confiriendo el derecho de réplica (Ekmekdjian, 1992), entre otros, a lo que debe agregarse los trascen- 
de constitucionalidad ${ }^{51}$, que ponen de manifiesto un poder creciente de los magistrados -denominado politización de los jueces ${ }^{52}-$, máxime que tales interpretaciones judiciales por parte de nuestro Alto Tribunal, al decir del Maestro Bidart Campos, adquieren el mismo rango de la Constitución interpretada y componen con ella una unidad ${ }^{53}$.

Tampoco podemos desconocer que la judicialización de los más variados problemas que se presentan en la sociedad ${ }^{54}$ les impone a los jueces -que son imparciales pero no indiferentes- llenar un espacio que no ocupan el resto de los poderes institucionales ${ }^{55}$.

A ello se le suman numerosas disposiciones de fondo que otorgan a aquellos un claro y expreso poder discrecional en el dictado de sus pronunciamientos, sin perjuicio de las que confieren las normas contenidas en los códigos procesales.

Por otra parte, debemos mencionar una caótica y endiablada legislación que se va elaborando sin ajustarse a las pautas de la técnica parlamentaria y que la torna incontrolable, incoherente, penetrante, fragmentaria y variable $e^{56}$, que impone imprescindible y necesariamente un aumento del poder discrecional de los magistrados. En tal sentido, se ha destacado que la creciente "esfumación" de la ley, por la recurrencia a preceptos "abiertos", flexibles, conceptos indeterminados, sus contrastes y "lagunas", tanto como el inmovilismo del legislador, terminan trasladando a los jueces funciones que son más propias de aquel, entonces, estos deben asumir tareas integrativas y de "suplencia judiciaria"57.

dentales pronunciamientos de la actual CSJN en materias como competencia originaria, delitos de lesa humanidad y terrorismo, control de convencionalidad, legitimación activa en derechos de incidencia colectiva, tutela de derechos laborales y sociales, etc.

51 Casos: "Mill de Pereyra", 2001; "Banco Comercial de Finanzas", 2004.

52 MORELLO, Augusto M. El derecho y nosotros. La Plata: Lib. Ed. Platense, 2000. p. 17.

53 BIDART CAMPOS, Germán J. Manual de la Constitución reformada”. Bs. As: Ed. Ediar, 1996. T० I. p. 276.

54 La explosión de la conflictividad colectiva se presenta en sectores muy diversos, como los que se relacionan con la defensa del medio ambiente, el patrimonio común histórico o artístico y paisajístico, la salud pública y las relaciones de consumo en general; como asimismo, en procesos de jurisdicción voluntaria, verbigracia, autorizaciones judiciales para actos personalísimos, como trasplantes de órganos, internaciones y tratamientos médicos, abortos, coberturas de prepagas, etc.

55 Omiten ejercer indelegables facultades: el Ejecutivo que no gobierna, a veces ni siquiera administra, sumado a la parálisis o excesiva morosidad del Legislativo.

56 MORELLO, Augusto M. "Motivación adecuada de la sentencia. Matices". Rev. El Derecho, Bs. As: Ed. Universitas SRL. To 224. p. 660.

57 PICARDI, N. "I mutanti del ruolo del giudice nei nostri tempi". Derecho Procesal en vísperas del siglo XXI. Temas actuales en memoria de los Profs. I. Eisner y J.A. Salgado. 
En ese contexto estimo que la presencia de genuinas potestades discrecionales, de manera alguna los exime del deber de proporcionar las argumentaciones que convenzan que sus pronunciamientos se ajustan a Derecho, es decir fundados en principios y valores que deben ser explicados clara y suficientemente.

Y ello es así, por varias razones: primero, por el deber de motivar sus decisiones; segundo, por cuanto los pronunciamientos judiciales, fundamentalmente los que emanan de la Corte Suprema, deben transmitir un mensaje persuasivo mediante argumentos y razones sustantivas que lleven intrínseca fuerza de convicción; y tercero, ya que el ejercicio de todo poder debe justificarse.

Asimismo debe destacarse que los legítimos poderes discrecionales de los jueces de primera instancia no excluyen a su debido contralor por parte de los tribunales de alzada, en la medida en que se excedan sus límites o se incurren en violación (relevante, grave y de modo disfuncional, en equivalencia al absurdo o arbitrariedad en la evaluación de lo fáctico o prueba) de los contenedores y el principio de razonabilidad, el sólido cimiento del edificio jurídico.

No hay sistema legal civilizado, marcaba Cappelletti, que no haya intentado diseñar y promulgar algunos límites a la libertad judicial, en ambas formas, sustanciales y de procedimiento. "Los primeros varían de época a época y de sociedad en sociedad mediante el juego de varios mecanismos: precedentes, opiniones, teorías, códigos, medios masivos, la presión de opinión pública, el cambio de las valoraciones, la intuición y sentimiento de la justicia, cualidades innatas en el político juez de la Corte. En cuanto a los límites procesales son consustanciales al proceso judicial de la misma naturaleza y lo integran. Aquí la reafirmación en concreto de las garantías es una conquista diaria de los fallos del Alto Tribunal"58.

Bien se verificó - señaló Morello- “cuán lejos están los jueces de ser "libres y privativos", personalísimos y subjetivos, en el uso de lo discrecional. Por huidizos o confundidos que fueren las palabras o los conceptos de los legisladores, el magistrado, en la labor hermenéutica, debe llegar a una certeza razonada; avalada por argumentación -controlable- exenta de caprichos o quiebras lógicas". Para concluir: "No hacer revisable el poder discrecional de los jueces

Coordinado por Roland ARAZI. Bs. As: Ed. Ediar, 1997. p. 398, citado por BERIZONCE, Roberto O. "Activismo judicial y participación en la construcción de las políticas públicas". Revista de Derecho Procesal (Número extraordinario conmemorativo del Bicentenario"), Sta. Fé: Ed. Rubinzal-Culzoni, 2010. p. 169.

58 CAPPELLETTI, Mauro. “El juez ¿elaborador de la ley o intérprete?”. Informe General de la Segunda Conferencia Internacional de Jueces de Apelación, Sydney y Camberra, Australia, 1980, citado por MORELLO, Augusto M. "La Corte Suprema. El aumento de su poder a través de nuevos e imprescindibles roles". Rev. El Derecho. Bs. As: Ed. Universitas SRL. To 112. p. 972. 
sería "preocupante" para los fines de la mejor protección de la jurisdicción y los derechos del litigante" 59 .

La esfera de la justicia es, al cabo, la que siempre señala los límites y confiere el examen final, por cuanto la ratio legis -la razón formal de la norma jurídicapuede oponerse a la ratio iuris, es decir, la razón de ser del Derecho, y esta es la que debe privar.

En dicha inteligencia, es forzoso convenir que no puede tenerse por racionalmente fundada una decisión que desconozca o contradiga la realidad de los hechos acreditada en la sustanciación del proceso; como tampoco puede considerarse racionalmente fundada una decisión adoptada sin evaluar todos los factores jurídicamente relevantes, ni tampoco la que haya introducido algún otro factor al que el ordenamiento no confiera relevancia alguna a esos concretos efectos. En atención a ello, puntualiza criteriosamente el catedrático madrileño Tomás-Ramón Fernández: "Una decisión no puede ser tenida como razonable, aunque supere el test de racionalidad, si es claramente desproporcionada. De este doble test, de racionalidad y razonabilidad, depende, pues, en último término, la distinción entre la discrecionalidad legítima y la arbitrariedad prohibida" 60 .

\section{COLOFÓN.}

Si bien la tendencia mundial es ampliar el poder discrecional del juez ${ }^{61}$, el mismo jamás es absoluto, pues, en el caso contrario aumentaría la imprevisión y la incertidumbre jurídica; esta siempre debe ser debidamente fundada y sujeta a

59 MORELLO, Augusto M. "La discrecionalidad judicial, límites y control en casación”, Rev. El Derecho. Bs. As: Ed. Universitas SRL. To 189. p. 571.

60 FERNÁNDEZ, Tomás-Ramón. "El derecho y el quehacer de los juristas". Rev. La Ley. Bs. As: Ed. La Ley SAE e I. 13.4.2012.

61 "La técnica jurídica ha ido abandonando el acatamiento de las normas escritas por el legislador y presta mayor atención que antes a la interpretación judicial, ya que pocos vestigios quedan de la antigua ideología de la exégesis. Los jueces se consideran -y sobre todos son considerados- libres de aplicar la ley, como les parezca justo, hasta tal punto que se los critica públicamente si obedecen el estricto texto de la ley de un modo que algunos grupos juzguen ofensivo para sus expectativas, deseos o intereses"; "si antes los jueces eran una especie de pequeños legisladores subordinados, encargados de una tarea interpretativa más o menos tímida respecto de los códigos y las leyes, ahora se encuentran por encima del legislador; y solo su prudencia, su acuerdo político o moral con esa reglas o su deseo de evitar reacciones airadas sirven para morigerar el ejercicio de aquella potestad que la sociedad les encomienda sin decirlo expresamente". GUIBOURD, Ricardo A. "Las tablas de la ley". Columna de opinión, Rev. La Ley, Bs. As: Ed. La Ley SAE e I. 15.2.2011. 
control y sus límites son las garantías constitucionales: la igualdad de las partes, el derecho a ser oído y el proceso justo, que implica el respeto a los principios de razonabilidad y de proporcionalidad en la búsqueda de un equilibrio entre la seguridad y la equidad.

En el juego de avance y contención de los poderes atribuidos a los magistrados, al Derecho siempre lo definen los límites; y, en materia de discrecionalidad judicial, el ejercicio de aquellos no debe entenderse como facultades y prerrogativas, sino en términos de responsabilidad jurisdiccional.

\section{REFERENCIAS.}

BERIZONCE, Roberto O. "Activismo judicial y participación en la construcción de las políticas públicas". Revista de Derecho Procesal (Número extraordinario conmemorativo del Bicentenario"), Sta. Fé: Ed. Rubinzal-Culzoni, 2010.

BIDART CAMPOS, Germán J. Manual de la Constitución reformada. Bs. As: Ed. Ediar, 1996. To I. p. 276.

-.----- Tratado elemental de Derecho constitucional argentino. Bs. As: Ed. Ediar, 1989. $\mathrm{T}^{\circ} \mathrm{I}$.

CARRIÓ, Genaro R. Notas sobre Derecho y lenguaje. 2a ed. Bs. As: Ed. Abeledo-Perrot, 1979.

CASSAGNE, Juan C. "La discrecionalidad administrativa y el control judicial". Rev. La Ley, Bs. As: Ed. La Ley SAE e I. To 2008-E.

DWORKIN, Ronald. Los derechos en serio. Traducido por Marta Guastavino. Barcelona: Ed. Ariel, 1992.

FERNÁNDEZ, Tomás-Ramón. "El derecho y el quehacer de los juristas". Rev. La Ley. Bs. As: Ed. La Ley SAE e I. 13.4.2012.

KELSEN, Hans. Teoría pura del derecho. Traducido por Roberto J. Vernengo. México: UNAM, 1979.

LORENZETTI, Ricardo L. Teoría de la decisión judicial. Fundamento de Derecho. Sta. Fé: Ed. Rubinzal-Culzoni, 3ª Parte, Cap. I, 2006.

MASCIOTRA, Mario. "Un Derecho Procesal para todos los tiempos... Desde Carlos V al tercer milenio". Rev. de Derecho Procesal. No 5, Sta. Fé: Ed. Rubinzal-Culzoni , 2000

MORELLO, Augusto M. "La discrecionalidad judicial, límites y control en casación”, Rev. El Derecho. Bs. As: Ed. Universitas SRL. T 189.

-..-.-. El derecho y nosotros. La Plata: Lib. Ed. Platense, 2000.

RODRÍGUEZ, César. La decisión judicial. El debate HART - DWORKIN. Bogotá: Ed. Siglo del Hombre, Univ. de los Andes, 1997.

VIGO, Rodolfo L. De la ley al derecho. México: Ed. Porrúa, 2005. 